\title{
A Comparison of Gender Equality Education Curriculum in Primary School in China and Finland
}

\author{
Hongyu Chen ${ }^{1, a, *}, \dagger$, Jinjin $\mathrm{Wu}^{2, \mathrm{~b}, *}, \dagger$ \\ ${ }^{1}$ University of Science and Technology Liaoning, Anshan, Liaoning, China \\ ${ }^{2}$ Ginling College, Nanjing Normal University, Nanjing, Jiangsu, China

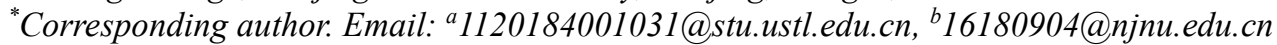 \\ "Those authors contributed equally.
}

\begin{abstract}
In the context of the prevalence of gender equality education, this paper examines the similarities and differences between China and Finland in terms of gender equality education curricula in primary schools. By collecting and analyzing relevant literature and analyzing three aspects: policy, curriculum and teacher training, a conclusion is drawn that gender equality education in Finland is better than that in China, and that there are clear differences in the three aspects mentioned above. Therefore, we expect China to learn from Finland's success cases and compensate for its own disadvantages.
\end{abstract}

Keywords: Gender equality education, Education policy, Curriculum.

\section{INTRODUCTION}

China is committed to universal gender equality education, but the results are not very visible. Since December 2018, gender equality education has been implemented in primary and secondary schools in Tianjin, China[1]. Many efforts have been made for gender equality education in China. However, in the Global Gender Gap Report 2021, Finland is ranked second, while China is ranked 107 th, indicating a difference in their progress in closing the gender gap[2]. Leaving aside the influence of hard factors such as some of the lessthan-satisfactory factors affecting gender equality education in China. This paper will therefore analyze the reasons for the gap and explore the factors involved.

Gender equality in education usually refers to equal opportunities for girls or boys to receive and participate in education and to obtain equal educational outcomes of high quality in terms of environment, processes and outcomes [3]. Gender inequality refers to the unequal distribution of certain resources between males and females and is "considered to indicate that less value is assigned to a particular group" [4]. Indeed, gender discrimination exists in primary school students' English learning, and this unknowingly affects their English learning. However, most of the research in China has been conducted from China itself, and there is little literature compared to other countries. Therefore, this paper will identify the reasons for the gap and explore the factors that contribute to the gap in gender equality education between China and Finland. It is hoped that this research will better contribute to gender equality education in China.

The methodology used in this study is a quantitative research approach. Firstly, we will focus on the impact of policies on gender equality education curricula in China and Finland. Secondly, we will analyze the differences in school practice between China and Finland, using the example of China and Finland. Finally, we will analyze some of the influencing factors through different approaches to teacher training. Based on this, we will analyze the reasons for the differences and plan for the future development of gender equality education in China.

\section{LITERATURE REVIEW}

\subsection{Gender equality and inequality}

Researchers have explored the topic of "gender equality in education" in various aspects in the international context. In the article "Gender Equality in Education: In Definitions and Measurements", Ramya Subrahmanian distinguishes the two concepts of "gender parity goals" and "gender equality goals" in education, and points out that the evaluation of the latter requires 
multiple clear indicators, which can be summarized as the realization of the right to education [5]. By analyzing survey data, Psaki et al. Chooses 43 countries and summarizes they have made some progress in achieving the international goal of gender equality in education, but also points out that many regions still face great difficulties and more measures need to be taken to narrow the gender gap in education [6]. The article "Coeducation and gender equality in the Education System: a Scoping Review" examines coeducation interventions as a means of promoting gender equality in education, highlighting the importance of schools and teachers to promote awareness of gender equality in children. These studies confirm some progress and present existing problems in terms of the current status of gender equality education from different perspectives [7]. Chinese scholars Tang et al. analyze the results of the questionnaire survey and found that the gender equality consciousness of Chinese students was weakest in primary school and college stage, suggesting that schools strengthen gender equality education in these two periods [8]. Shi Yan and Tang Qiyuan analyze the deficiencies of teachers, curriculum themes and content in implementing gender education in Chinese schools [9]. Mervi Heikkinen et al.'s report explores promising approaches to gender equality education in Northern Europe and summarizes the benefits these countries have gained from it [10].

\section{MAIN BODY}

\subsection{The impact of policy on gender equality education curriculum}

Both China and Finland have policies to promote gender equality in primary education, while their impacts on gender equality education curriculum are different. Since the "Compulsory Education Law" was promulgated in 1986, China began to mention the content of "gender equality in education" in policy texts [11]. Nevertheless, this requirement is not reflected in the school curriculum. Until the "12th Five-Year Plan for the Development of National Education" issued in 2012, the description of gender equality education was still general and too simple. In the national document, "gender equality education" does not seem to be a pressing issue, and there was little content about training teachers' gender equality awareness in teaching. In 2011, "the Outline for Women's Development in China (20112020)", issued and implemented by The State Council of the People's Republic of China, proposed that gender equality education should be considered in the formulation of curricula and teaching materials to improve the gender awareness of educators [11].

In the following years, some provinces and cities in China gradually began to increase the planning and implementation of gender equality education courses. Due to the huge area of China and the large number of provinces and cities, the development of different regions is very uneven, the curriculum and teaching materials used in different regions are also different, and the rights of women and children vary greatly, making it difficult for the whole country to formulate unified standards. As a result, each region in China has developed different rules and regulations for its own situation, and gender equality has been integrated into education to varying degrees.

Taking Tianjin as an example, the relevant department has provided a guarantee for gender equality education by issuing the relevant document "Notice on carrying out gender equality education in primary and secondary schools in Tianjin"and supplied training and guidance on gender equality education for all school teachers, which will promote the implementation process and speed up the curriculum coverage. Under these policies, primary schools in Tianjin have set up gender equality working groups to design a batch of gender equality education courses based on local features and students' needs and integrate them into their daily teaching.

Compared with the situation in China, Finland's efforts to promote gender equality in education are more systematic and have a longer history, dating back to the establishment of the Gender Equality Education Commission in 1988, with the aim that to find out what new responsibilities need to be given to education in the formulation of gender equality legislation [12]. Finland attaches great importance to teacher training, considering that teachers have a subtle influence on students in school education, such as classroom teaching, teacher-student interaction, daily life communication and so on. The basic qualification for primary and secondary school teachers in Finland is set as a master's degree, which ensures the high quality of teachers. Therefore, they also regard teacher education as the key to promoting gender equality in education, expecting teachers to be the main force to promote gender equality on campus and in society.

In Finland's the Act on Equality between Women and Men of 2015, it is clearly stated that compulsory schools are required to implement gender equality programs as well as higher education [10]. Based on the requirements of this act, the Ministry of Education of Finland launched the "TASUKO" project, involving a wide range of educators and experts across the country to form an educator network. It reviews and evaluates the curriculum of teacher education, checks whether there is gender equality content, and encourages scholars and teachers to reflect and research on gender equality in teaching. With the support of this project, many teacher education institutions have set up corresponding courses on gender equality, aiming to improve teachers' gender awareness and assist the institutions in carrying out the special responsibilities of schools as set out in the Act. 
"Gender awareness" in the project means "an awareness of the inequalities that are taking form in the practices and processes of schools and education and to an awareness that those practices can be changed" [13]. This indicates that they believe there is a hidden danger of gender inequality in school education, and this situation can be improved through teachers' reflection and practical operation.

Comparing China's policies of gender equality education curriculum with those in Finland, the description of gender equality education in China's national documents is still very young and inadequate. In specific regions, like in Tianjin City, their gender quality education curriculum is still in the early stages of experimentation and, like the policies, needs to be evaluated and adjusted. In addition, Finland attaches great importance to the training of teachers' gender equality awareness, which is lacking in China. Despite the requirement for gender equality awareness in teacher training, it is not widely available in China, just a little training in some areas, and there is still a long way to go in this country where gender inequality is deeply rooted.

\subsection{Practice is easier for pupils to accept than teaching concepts}

In terms of curriculum implementation in Tianjin, China and Finland also have many differences, which will directly lead to children's different acceptance of gender equality curriculum. For example, the "Youth Association" of Jiankai middle school in Dongli District in Tianjin, carried out a big discussion on "gender equality" [14]. The members of the "Youth Association" have investigated the actual situation of gender equality from three aspects: daily life and customs, traditional media and new media [14]. They will collect and sort out the information, confusion and thinking, and communicate in the discussion actively.

The same thinking and enlightenment also appeared in the classroom of Zhao Baopeng, a teacher of Shuishang Primary School in Nankai District in Tianjin [14]. He specially created a unique teaching plan for his teaching class: game introduction, situational theater, and a video of $\mathrm{Tu}$ Youyou. Teachers and students interact frequently in the classroom. Through different situations at different levels of class, family and society, students can "immerse themselves" to understand the diversity of gender roles in different fields.

However, the gender equality curriculum in Tianjin has not considered the wishes of children from beginning to end. At the same time, we also found that most gender equality courses in Tianjin are mainly taught by teachers, which is no different from ordinary subject teaching. Moreover, pupils' learning of new knowledge depends on their own specific experience, so their acceptance of learning is greatly limited and is only feasible in a certain range [15]. Therefore, compared with the gender equality curriculum in China, the curriculum in Finland will be more flexible, focusing on some hands-on courses, which can attract the interests of different children.

In Finland, many courses in the primary school curriculum are taught jointly by boys and girls, such as technology. The class is divided into two parts, and the other half learns hard material technology with teachers and colleagues (they make their own design lamps from wood, metal or plastic). Another teacher teaches the other half, and then each student creates their prints. They draw, punch and form prints on the fabric. Finally, they used these printed fabrics to make a bucket or an information box [16]. This implicit curriculum will provide children with more thinking space. Through the form of hands-on curriculum, children can more deeply experience the gender equality curriculum, rather than imparting relevant knowledge and concepts like Tianjin, which can not fundamentally affect children's understanding of gender equality.

In short, taking Tianjin as an example, the main forms of gender equality education in China have not changed much, and the specific acceptance level needs to be based on the absorption level of children. To sum up, Finland will be more advanced than China in content and form, so the progress of gender equality will be better.

\subsection{Different emphasis on gender equality awareness training for teachers}

Chinese team members are mainly experts, leading all teachers in pilot schools to carry out gender equality education business training and teaching guidance, and there is no assessment in whole process, just a training for teachers [17]. The training method in China is centralized training, which brings all teachers together for training. This method is lack of pertinence. Because there are many teachers in a school, the effect of training teachers in all pilot schools is not prominent. If teachers are not well trained, the gender equality education curriculum cannot play a great role for students.

In Finland, taking the "TASUKO" project as an example, with the support of this project, many teacher education institutions have set up corresponding courses on gender equality, aiming to improve teachers' gender awareness and assist the institutions in carrying out the special responsibilities of schools as set out in the Act. "Gender awareness" in the project means "an awareness of the inequalities that are taking form in the practices and processes of schools and education and to an awareness that those practices can be changed" [13]. This indicates that they believe there is a hidden danger of gender inequality in school education, and this situation can be improved through teachers' reflection and practical operation. 
For teacher training, the program chose not to work with deans and administrators, but with committed feminists activists, bringing together small groups of teachers and researchers in the form of regular seminars, courses, and small-scale studies [18]. They discuss vital concepts and strategies, concerning "ethnicity, age, sexuality and health, as well as with local and cultural opportunities and differences" [18]. Therefore, their consideration of gender equality is not limited to the narrow sense of equality between women and men, but involves more and broader social and cultural factors, which makes their thinking more comprehensive and practical.

However, the problem with this project is that it requires a lot of money. As one of the largest gender equality projects in Finland, it received more than 600,000 euros in funding from the Ministry of Education [12]. While funding and training resources tend to run out, there is a tendency for such courses and research to be carried out only by women's rights activists, who are taking on too much responsibility and facing more difficulties to gather educators for group discussions.

By contrast, teacher training in China is still woefully inadequate. Although the policy requires gender equality in teacher education, it is still much more vague than in Finland. In practice, Finland spends more money and energy on teacher training to promote various programs and programs, while China's training time is shorter and it is difficult to achieve useful results. Because teachers in the school education is an important part of their words and deeds and fully integrated into teaching methods in dealing with students' daily, so only two countries are making requirements to teachers' gender equality awareness training, to hope the teacher can not only gender equity education course on to students achieve better effect, but can also have a positive impact on students' attitudes towards gender equality in school life. However, by comparison of the two country's teacher education gender equality awareness training, we can see a significant difference, which may explain why China's course of gender equality in so far has not achieved significant results, because the teacher himself has not been sufficient professional training in this respect, it is difficult to have positive influence on students. Gender equality education is still an underappreciated subject in vast China.

\section{CONCLUSION}

The differences between China and Finland in gender equality education are mainly reflected in the specific implementation of policies, courses and the training of teachers. In terms of policy, Finland's gender equality policy is more specific, laws and regulations are more comprehensive, and the policy is promulgated earlier, so there will be more time to correct errors in the implementation process. However, China's policy is promulgated later and has less experience, so it will be more difficult to implement than Finland. Secondly, in terms of the specific implementation of the curriculum, most of the courses in China are taught by teachers, which is no different from ordinary subject teaching, but Finland is different. Finland is dominated by teachers and takes children to play games or practice. Although there is little knowledge about the concept of gender equality, it is instilling equality knowledge into children in every practice. For example, they have embroidery classes and baseball classes together. This makes children form the concept of equality from an early age. Finally, teacher training can better see the gap between the two countries. China's training pays too much attention to form. All teachers train together without pertinence, and there is no assessment in the end, which cannot guarantee the acceptance of teachers. Finland has regular assessment tasks, and teachers will be divided into several groups to discuss their views and promote communication.

Finland's success in the implementation of gender equality curriculum has a certain basis, and some problems have been handled well in the whole process. China can appropriately learn from Finland's practices to make up for its shortcomings, and Finland is a good reference for the promotion of gender equality in the world.

\section{REFERENCES}

[1] Huiying L. The Concept and Practice of Gender Equality Education. Journal of China Women's University. 2021;3:90-7.

[2] Global Gender Gap Report, World Economic Forum, Mar. 2021.

[3] European Institute for Gender Equality. Gender equality glossary and thesaurus, 2018.

[4] Forsberg, E., \& Olsson, L. Gender Inequality and Internal Conflict. Oxford Research Encyclopedia of Politics. Retrieved 19 Oct. 2021.

[5] Ramya Subrahmanian, Gender Equality in Education: In Definitions and Measurements, International Journal of Educational Development 25, 2005, 395407.

[6] Stephanie R. Psaki, Katherine J. Mccarthy, Barbara S. Mensch, "Measuring Gender Equality in Education: Lessons from Trends in 43 Countries, Population and Development Review 44(1): 117-142, March 2018.

[7] María Aragonés-González, Ana Rosser-Limiñana, Diana Gil-González, Coeducation and gender equality in the Education System: a Scoping Review, Children and Youth Services Review, Volume 111, 2020, 104837, ISSN 0190-7409, 
DOI:https://doi.org/10.1016/j.childyouth.2020.104 837

[8] Tang Wenwen, Ge Xiaosong, Zhao Ying, "Gender Differences in Primary School Students' Sociality Adaptation", Journal of Inner Mongolia Normal University (Philosophy \& Social Science) Mar.2011, Vol.40 No.2.

[9] Shi Yan, Tang Qiyuan, Exploration of Core Literacy in the Construction of Gender Equality Education Curriculum, Journal of China Women's University, Sept. 2021 No.5.

[10] Mervi Heikkinen, Mia Heikkilä, Cecilie Nørgaard, et al., Promising Nordic Practices in Gender Equality Promotion in Basic Education and Kindergartens, 2016.

[11] Zheng Lei, Li Jing, Review and evaluation of gender equality policy in Education in China, 2012.

[12] Yi Hongjun, Chen Yao, Gender Equality in Teacher Education in Finland: Measures, Achievements and Reflections, Journal of Hebei Normal University (Educational Science) Sep 2020, Vol. 22 No. 5.

[13] Helakorpi J., Lehtonen J., Lahelma E., et al., Research on Gender Awareness in Teacher Education, 2010.

[14] Gao Li, Universal gender equality education in primary and secondary schools in Tianjin: "little man" has a stereotype, 2018.

[15] Liu Yanling, Wu Mingxia, Characteristics of lower grade students' acceptance of learning in primary school, 2019.

[16] Learning Scoop, An ordinary day at Finnish school, 2019.

[17] China Women's daily, Implement the basic national policy of gender equality and comprehensively promote gender equality education in primary and secondary schools in the new era, 2019.

[18] Kreitz-Sandberg S., Lahelma E, Global DemandsLocal Practices: Working towards Including Gender Equality in Teacher Education in Finland and Sweden, 2021. 